\title{
A Matter of Gravity: Will Space Station Freedom Devour Materials Science?
}

\author{
Robert L. Park
}

The rules of the budget game have abruptly changed. The agreement reached between the White House and Congress in October put spending on a no-growth diet for the next three years. That's bad enough, but when materials science steps on the scales, it could find an 800-pound gorilla sitting on its shoulders. The $800-$ pound gorilla is microgravity research.

Under the new rules, funds cannot be shifted between domestic, foreign, and defense programs. If there were a "peace dividend," for example, it couldn't be used to reinforce the nation's crumbling science base. Among domestic programs, spending in one area can be increased only if a corresponding cut is absorbed somewhere else. This "zero-sum game" is certain to increase the tension between the National Science Foundation and NASA, which share the same appropriations subcommittee allocation. To see why this poses a particular threat to materials research, we need to review NASA's plans for a manned space station.

When President Bush took office, he endorsed the space station project as a sort of microgravity R\&D lab that would develop wonderful new materials for U.S. industry. It was a concept inherited from the Reagan administration, which was fond of referring to space as "just another place to do business." The myth that industry is eager to exploit the commercial potential of microgravity seems to have been accepted uncritically in Washington. One company, Space Industries Inc., headed by former astronaut Joe Allen, even proposed in 1987 to build an automated commercial space laboratory to conduct research and produce new materials in weightlessness. The commercial space laboratory was intended to get U.S. industry started on space manufacturing before the manned space sta- tion could be in operation some time around the bi-millennium.

A robot space laboratory was not an altogether bad idea. It had two great virtues: without the need to sustain a crew, it could be built far more quickly and cheaply than a manned laboratory; and, without a bunch of astronauts bumping around, it would come much closer to zero gravity. Space is quiet and clean; it is humans who are noisy and dirty.

When put to the test, however, private industry couldn't think of any weightless things it really wanted to do-at least not

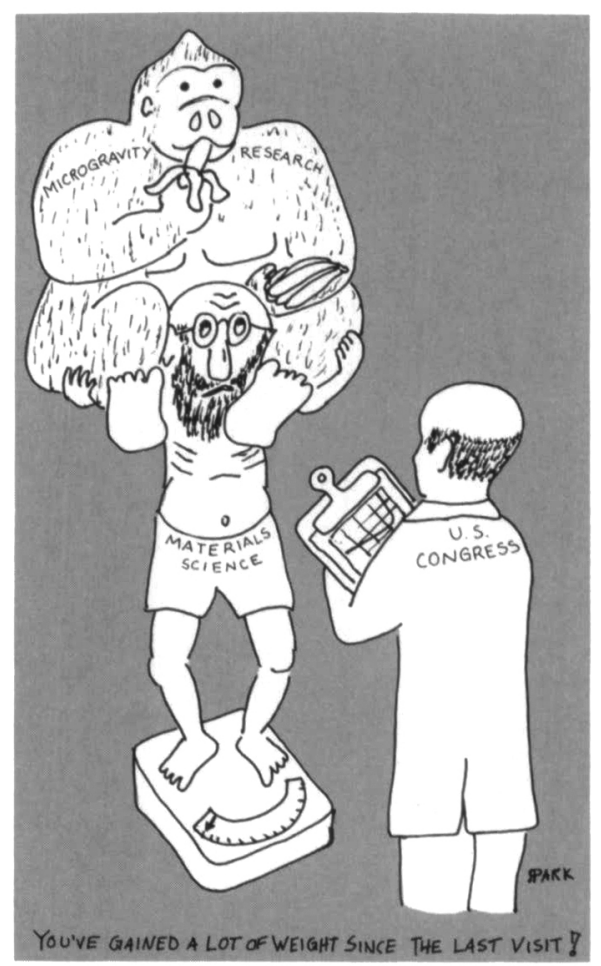

badly enough to pay for them. Manufacture ball bearings? Ball bearings made here on earth simply are not a problem. Grow more perfect semiconductor crystals? Same response. And it's not at all clear that more perfect ball bearings or crystals could be produced in space. The plan finally died when a National Research Council panel concluded that most of the microgravity research that makes sense could be done on the shuttle. It does not, as they say, take a rocket scientist to see that the same arguments apply to Space Station Freedom.

Congress, however, continues to emphasize microgravity research on the space station. In October, Congress directed NASA to scale down its space station plans, which by now were being estimated to cost an astronomical $\$ 38$ billion. $\$ 1.9$ billion was appropriated for the space station in FY 1991, and NASA was told it should plan for that to grow at a mere $10 \%$ per year. NASA could do this, Congress suggested, by adopting an incremental approach, with the station being developed in phases. The first phase, Congress said, should be an astronaut-tended microgravity facility. Beyond the bizarre circumstance of the Senate Appropriations Committee staff telling NASA engineers how to design the space station, Congress was still focusing on microgravity.

A $10 \%$ growth rate may seem austere to NASA's expansive planners, but in a zerosum game it could mean major cuts for NSF. Moreover, the cuts could be expected to come disproportionately at the expense of materials research. Who would listen to pleas for increased spending on materials research at NSF while NASA was putting $\$ 2.5$ billion per year into materials research in the form of a microgravity lab?

Help has come from an unlikely quarter. In August Vice President Dan Quayle appointed the Advisory Committee on the Future of the U.S. Space Program, headed by Norm Augustine, the CEO of Martin Marietta, to review the civil space program and recommend future goals. There was widespread skepticism that a panel of NASA insiders and contractors could be expected to advise the president (who had personally endorsed major NASA programs) to institute fundamental reforms. Although the language avoids confrontation, the recommendations of the Augustine committee, if adopted, would transform NASA.

By now the problems of the space station program have received widespread publicity. As designed, Space Station Freedom is overweight and underpowered, depends on a shuttle fleet that is often grounded, 
requires far too much risky outside maintenance, and has no discernible mission. The Augustine panel calls for drastic rethinking of the space station: "We do not believe Space Station Freedom, as we now know it, can be justified solely on the basis of the (nonbiological) science it can perform, much of which can be conducted on earth or by robotic spacecraft for less cost."

The Augustine report identifies experimentation on the effects of a space environment on humans as the appropriate focus of a space station, with materials research given a secondary role. More im-

\section{The materials science community must not remain silent in the de- bate over the future of the U.S. space program.}

portantly, adoption of the panel's recommendations would have the effect of delaying the space station program to around the turn of the century.

The coming weeks will witness a historic debate over the future of the U.S. space program. In that debate, the materials science community must not remain silent. The importance of microgravity to materials research and development must be placed in proper perspective.

Robert L. Park is a professor of physics at the University of Manyland, and director of the Washington, DC Office of the American Physical Society.

\section{MRS Spring Meeting \\ April 28 - May 2, 1991 San Francisco Marriott Anaheim, California}

\section{MeV Ion Beam}

The Pelletron Accelerator Systems range in terminal potential from $100 \mathrm{kV}$ to 25 MV for RBS, PIXE, AMS, and NRA and other applications. The NEC beam line components are ultra-high vacuum compatible. The NEC acceleration tubes are metal-ceramic bonded and fully bakeable. All NEC valves are metal sealing.

\section{- Beam Steerers \\ - Raster Scanners \\ - Slit Systems \\ - Faraday Cups \\ - All Metal Valves \\ - Fast Closing Valves \\ - Ion Sources \\ - RBS and PIXE \\ Systems and components in 36 countries. \\ - Beam Profile Monitors \\ - Electrostatic Lenses \\ - Beam Line Insulators \\ - Foil/Target Changers \\ - Gas Metering Valves \\ - Titanium Sublimators \\ - Accelerator Tubes \\ - Light Link Systems}

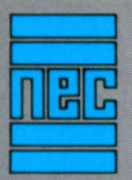

Graber Road, Box 310

Middleton, Wisconsin 53562-0310

Tel. 608/831-7600 • Telex 26-5430 • Fax 608/256-4103

\section{Systems and Components}
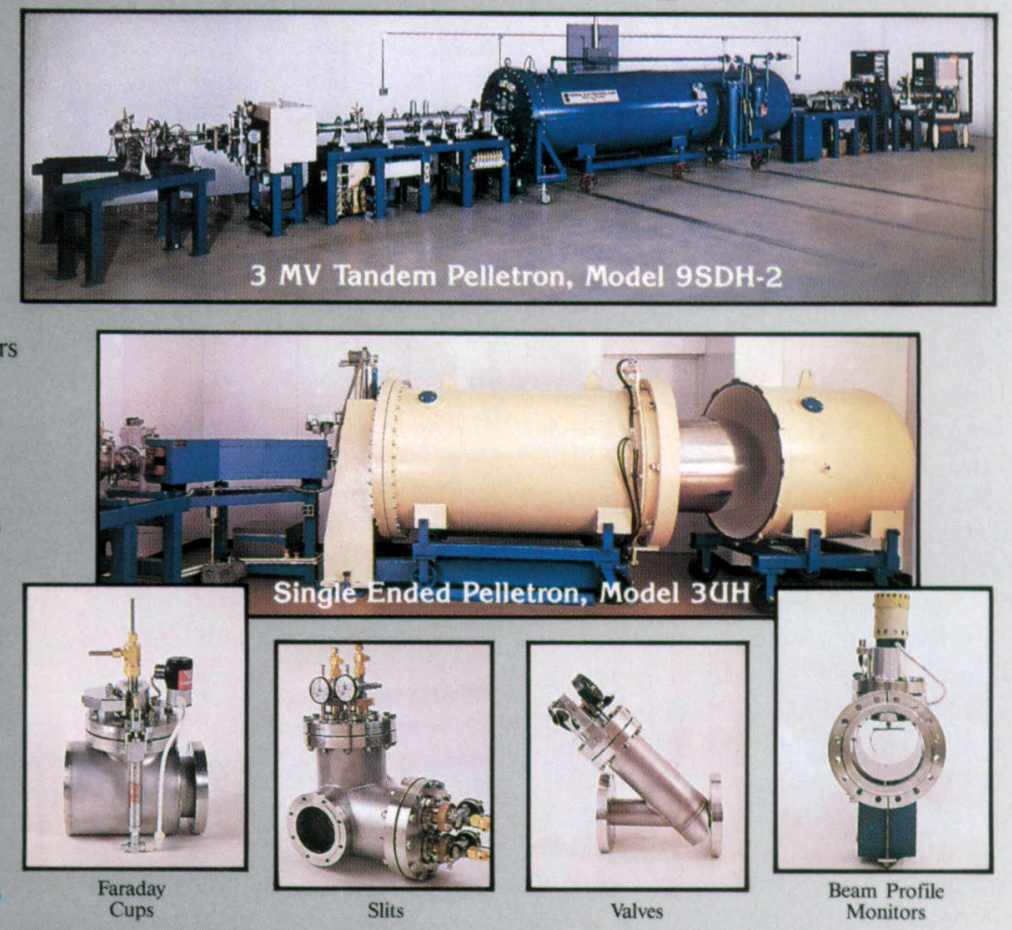

Circle No. 6 on Reader Service Card. 